\title{
Os efeitos da introdução de uma nova ferramenta de ensino nas práticas docentes em sala de aula - o caso de uma sequência didática ${ }^{1}$
}

\author{
Luciana Graça* \\ Luísa Álvares Pereira**
}

\begin{abstract}
Resumo
A nossa contribuição inscreve-se no quadro das investigações atinentes ao trabalho do professor e ao objeto ensinado. Área esta, na verdade, ainda pouco desenvolvida mesmo no plano internacional. Depois de uma breve apresentação das principais problemáticas teóricas norteadoras do nosso estudo, descreveremos a pesquisa empírica realizada. O estudo foi feito junto de seis professores - e das suas respetivas turmas - a lecionar língua portuguesa ao $6^{\circ}$ ano de escolaridade e procurámos analisar, precisamente, o trabalho do professor em sala de aula, centrando-nos na análise da forma como a introdução de uma nova ferramenta de ensino - no caso, uma sequência didática para a escrita do artigo de opinião -, a mobilizar pelo professor, poderia desencadear transformações quer no plano das práticas de ensino propriamente ditas quer no próprio objeto de estudo ensinado. Assim, é nosso intuito, muito particularmente, fornecer dados que contribuam para a discussão em torno da importância das ferramentas de ensino de que o docente dispõe e/ou pode dispor, na sua práticas de ensino.
\end{abstract}

Palavras-chave: ferramenta de ensino; ensino da produção escrita; sequência didática.

\section{The effects of the introduction of a new teaching tool in teaching practices in the classroom - the case of a} didactic sequence

\begin{abstract} in their teaching practice.

Keywords: teaching tool; writing; didactic sequence.

\section{A problemática: do quadro teórico ao dispositivo de pesquisa montado}

\section{Quadros teóricos de referência}

A análise dos materiais didáticos mobilizados pelo professor em sala de aula inscreve-se no conjunto das pesquisas que, dentro do quadro geral das Ciências Humanas e no da Didática mais em particular, se interessam pela análise do ensino tal como ele realmente acontece e é, in loco, em interação professor-alunos (BRONCKART \& LAF, 2004; TARDIF \& LESSARD, 1999, MACHADO, 2004), assumindo assim esta nova via de pesquisa um grande pendor descritivo (GOIGOUX, 2002, p. 126). Ora, acontece que, nesta nova linha de investigação, o ensino é

* Endereço eletrônico: lpereira@ua.pt

** Endereço eletrônico: lucianagraca@ua.pt
\end{abstract}

Our contribution falls within the framework of the researchs about the work of the teacher and the taught object. This area, in fact, is still undeveloped even internationally. After a brief presentation of the main theoretical issues guiding our study, we will describe the empirical research. The study was conducted with six teachers and their respective classes - of Portuguese language, in the 6th grade, and sought to analyze, precisely, the work of the teacher in the classroom, focusing on the analysis of how the introduction of a new teaching tool - in this case, a didactic sequence for writing an opinion article -, that will be mobilized by the teacher, could trigger changes both in terms of teaching practices or the taught object itself. Thus, it is our aim, more particularly, to provide data that contribute to the discussion on the importance of the teaching tools that the teacher could have

concebido como um outro qualquer trabalho, não obstante as suas especificidades indiscutíveis. E, neste sentido, a questão dos materiais didáticos emerge como uma questão central. Vejamos melhor a explicação. Se considerarmos o professor como um outro qualquer trabalhador numa outra qualquer atividade de trabalho, admitimos que ele se servirá de determinadas ferramentas para realizar, precisamente, no caso, o seu trabalho de ensino. E, ao advogarmos tal conceção sobre as ferramentas de ensino, situamo-nos, pois, numa análise marxiana do trabalho. Para Marx, este último é constituído por três elementos: a atividade pessoal do homem, o objeto sobre o qual o trabalho age e o meio pelo qual ele age. $\mathrm{O}$ autor define o terceiro elemento da seguinte forma: "uma coisa ou um conjunto de coisas que o trabalhador introduz entre ele próprio e 
o objeto de trabalho e que lhe serve de efetivo elemento condutor da sua atividade sobre este mesmo objeto" (1867/1993 - tradução nossa). Mas para que servem tais ferramentas? No dizer de Schneuwly (2000), estas contribuem para transformar um dado "objeto"; no caso do ensino, e segundo o mesmo autor, estamos a falar dos "modos de pensar, de falar e de fazer" dos alunos (tradução nossa). Porém, concretamente, quais são as ferramentas do professor? Naturalmente, não iremos aqui fazer uma listagem - até porque tal trabalho seria, além de hercúleo, impossível, ou, pelo menos, quase impossível. De facto, são numerosas as ferramentas, que tanto podem ser de ordem material como do discurso. Além disso, consideramos que o mais interessante será para elas olhar na própria situação de uso em que aparecem. Ainda assim, avançamos uma distinção que nos parece operatória. Plane e Schneuwly (2000) distinguem as ferramentas em sentido restrito, que implicam um dado dispositivo material independente de uma determinada prática (quadro negro, ferramenta informática...) e as ferramentas em sentido lato, que consistem, mormente, em práticas estabilizadas, que foram transmitidas, designadamente, pela formação ou por troca entre os próprios colegas, sem suporte material estável (tarefa, instrução dada, dispositivos didáticos...). Aduza-se que a estas ferramentas aqui referidas, a título exemplificativo, se acrescentam os conhecidos manuais, que integram os dois anteriores grupos. Por outro lado, importa destacar também que, e ainda numa perspetiva marxiana, este poder transformador da ferramenta é igualmente visível naqueles que as utilizam. Por outras palavras, a ferramenta pode transformar não só aquilo sobre que se aplica, como também o próprio trabalhador (RABARDEL, 1997). Ora, a nossa pesquisa interessa-se, precisamente, por equacionar o que poderá estar em causa aquando da escolha de uma e não de outra ferramenta didática. Assim, qual seria então a eventual ação dessas ferramentas sobre o trabalho propriamente dito? Sobre as próprias práticas de ensino do professor? Acontece que a nossa pesquisa apresenta ainda um outro foco de interesse: a eventual influência exercida por essa mesma ferramenta didática no "objeto" sobre que se aplica. Realidade investigativa esta, aliás, para a qual só muito recentemente se tem dirigido o enfoque das pesquisas na área (SCHNEUWLY \& THÉVENAZCHRISTEN, 2006; SCHNEUWLY, CORDEIRO \& DOLZ, 2005, p. 79; Schneuwly \& Cordeiro, 2005). O estudo desta realidade investigativa é na mesma linha por nós também feito à luz da teoria da transposição didática (BRONCKART \& PLAZAOLA-GIGER， 1998; CHEVALLARD \& JOHSUA, 1991). Para sermos mais precisas, inscrevemo-nos no segundo nível desta teoria. No primeiro nível, há a transformação dos conhecimentos científicos em objetos de ensino, como é o caso dos programas, dos livros didáticos... No segundo nível, assiste-se, agora, à reconstrução dos objetos de ensino em sala de aula, em plena interação didática professor-alunos. Objeto este reconstruído que adquire nesse momento a designação de "objeto (efetivamente) ensinado".

\section{Dispositivo de pesquisa montado}

A nossa investigação (GRAÇA, 2010) visa então analisar como as ferramentas didáticas (no caso, uma sequência didática - GRAÇA, 2010; DOLZ, NOVERRAZ E SCHNEUWLY, 2001; PEREIRA, 2000; PEREIRA \& CARDOSO, 2013) podem transformar quer as práticas docentes quer a própria forma como um determinado objeto inscrito no programa oficial de português como objeto a ensinar (em concreto, o artigo de opinião escrito CORDEIRO \& SCHNEUWLY, 2005; GRAÇA, 2010) é (re)construído em sala de aula através do trabalho do docente em interação com a turma.

Para tal, montámos o seguinte dispositivo de pesquisa, que comportou duas fases principais e um momento intermédio. Na primeira fase, a fase 1 - que decorreu durante o $2 .^{\circ}$ período do ano letivo de 2005/2006 -, cada professor ensina o objeto de ensino definido segundo a sua própria planificação, estipulando a duração e os eventuais materiais a utilizar em sala de aula. Designámos esta sequência de ensino de "comum", não obstante se reconheça que a presença da investigadora, por mais discreta que possa ser, torna a situação não (tanto - pelo menos) comum. Por seu turno, na segunda fase, a fase 2 - que decorreu durante o $3 .^{\circ}$ período -, o professor ensina o mesmo objeto de ensino, mas, desta vez, com a nova ferramenta didática facultada pela investigadora: uma sequência didática, distribuída a cada professor. Continua a caber a cada docente definir a duração e os materiais da sequência didática a utilizar. Por outro lado, note-se que nenhuma explicação foi dada a cada professor, quanto à forma como tal material poderia ser utilizado. Todas as aulas foram objeto de gravação audiovisual. Complementarmente, entrevistas de explicitação, semidirigidas, e com objetivos 
distintos, foram ainda realizadas, antes e após cada uma das duas grandes etapas. Antes do término da pesquisa, uma outra entrevista, também semidirigida, ainda que com determinadas especificidades em relação às restantes, foi também efetuada. A figura seguinte ilustra o desenho da investigação.

Figura 1 - Desenho da investigação

\begin{tabular}{|c|c|c|c|}
\hline Entrevista ante & & Entrevista ante & \\
\hline $\begin{array}{c}\text { Sequência de ensino } \\
\text { "comum" }\end{array}$ & \multirow{13}{*}{$\begin{array}{l}\text { Distribuição } \\
\text { de uma } \\
\text { sequência } \\
\text { didática } \\
\text { (SD) }\end{array}$} & $\begin{array}{c}\text { Sequência de ensino } \\
\text { com SD }\end{array}$ & $\begin{array}{l}\text { Entrevista } \\
\text { em diferido }\end{array}$ \\
\hline Entrevista post & & Entrevista post & \\
\hline Entrevista ante & & Entrevista ante & \\
\hline $\begin{array}{c}\text { Sequência de ensino } \\
\text { "comum" }\end{array}$ & & $\begin{array}{c}\text { Sequência de ensino } \\
\text { com } S D\end{array}$ & $\begin{array}{l}\text { Entrevista } \\
\text { em diferido }\end{array}$ \\
\hline Entrevista post & & Entrevista post & \\
\hline Entrevista ante & & Entrevista ante & \\
\hline $\begin{array}{c}\text { Sequência de ensino } \\
\text { "comum" }\end{array}$ & & $\begin{array}{c}\text { Sequência de ensino } \\
\text { com } S D\end{array}$ & $\begin{array}{l}\text { Entrevista } \\
\text { em diferido }\end{array}$ \\
\hline Entrevista post & & Entrevista post & \\
\hline Entrevista ante & & Entrevista ante & \\
\hline $\begin{array}{c}\text { Sequência de ensino } \\
\text { "comum" }\end{array}$ & & $\begin{array}{c}\text { Sequência de ensino } \\
\text { com } S D\end{array}$ & $\begin{array}{l}\text { Entrevista } \\
\text { em diferido }\end{array}$ \\
\hline Entrevista post & & Entrevista post & \\
\hline Entrevista ante & & Entrevista ante & \\
\hline $\begin{array}{c}\text { Sequência de ensino } \\
\text { "comum" }\end{array}$ & & $\begin{array}{c}\text { Sequência de ensino } \\
\text { com SD }\end{array}$ & $\begin{array}{l}\text { Entrevista } \\
\text { em diferido }\end{array}$ \\
\hline Entrevista post & & Entrevista post & \\
\hline FASE 1 & Fase intermédia & FASE 2 & \\
\hline
\end{tabular}

\section{Um caso empírico - alguns resultados sobre as transformações operadas pelos materiais didáticos}

Analisaremos, de seguida, um exemplo concreto: o caso de MAS, umas das professoras que colaboraram na nossa investigação, comparando a sequência de ensino da fase $1 \mathrm{com}$ a da fase 2 , à luz de dois principais vetores: o fator tempo, os textos utilizados e as atividades dominantes. Análise esta (GRAÇA, 2010) só possível, aliás, depois de termos elaborado as sinopses de cada uma de tais sequências (para mais informações a respeito deste instrumento metodológico, consultar, por exemplo, SCHNEUWLY, DOLZ \& RONVEAUX, 2006; GRAÇA, 2010).

\section{Fator tempo}

A duração temporal de cada uma das sequências de ensino de MAS é distinta, como podemos verificar a seguir.

\begin{tabular}{|l|l|}
\hline \multicolumn{2}{|c|}{ Sequência de ensino 1 } \\
\hline P1 & P2 \\
\hline 29-03-06 & 29-03-06 \\
\hline \multicolumn{2}{|c|}{ Quadro 1. Fator tempo - Fase 1 } \\
\hline
\end{tabular}




\begin{tabular}{|l|l|l|l|l|l|l|l|}
\hline \multicolumn{7}{|c|}{ Sequência de ensino 2 } \\
\hline P1 & P2 & P3 & P4 & P5 & P6 & P7 & P8 \\
\hline $19-04-$ & $19-04-$ & $24-04-$ & $24-04-$ & $26-04-$ & $26-04-$ & $03-05-$ & $03-05-$ \\
06 & 06 & 06 & 0.6 & 06 & 06 & 06 & 06 \\
\hline
\end{tabular}

Quadro 2. Fator tempo - Fase 2

O tempo consagrado ao objeto ensinado é, como vimos, significativamente mais longo na sequência de ensino da fase 2 . Entre as razões que podem ser avançadas, há uma que se afigura capital: a sequência didática proposta - com todas as atividades sugeridas, com todos os materiais disponibilizados - convida à realização de uma longa sequência de ensino (mais) longa. Isto, porém, aduza-se, apesar de MAS ter feito várias escolhas em relação ao material recebido; concretamente, muito do proposto na sequência didática é deixado de fora. Porém, a verdade é que, e não obstante tal significativa diferença registada, as sequências são relativamente compactas.

\section{Textos utilizados}

Na sequência de ensino da fase 1, MAS escolhe uma expressão retirada da parte final de uma obra de leitura obrigatória, trabalhada pela turma. Expressão esta, na realidade, em torno da qual gravita todo o trabalho da sequência. $\mathrm{Na}$ sequência de ensino da fase 2, MAS utiliza alguns dos textos fornecidos na sequência didática distribuída. Na sequência de ensino da fase 1, o centro do trabalho é a compreensão da referida expressão e a produção de conteúdo passível de ser integrado no texto a produzir. $\mathrm{Na}$ sequência de ensino da fase 2 , os textos utilizados devem já permitir um trabalho sobre as características do género em estudo. A perspetiva adotada por MAS na escolha dos textos sobre os quais os alunos são chamados a trabalhar sofreu, assim, uma evidente transformação.

\section{Atividades dominantes}

Quais são os principais procedimentos de ensino-aprendizagem presentes na sequência de ensino da fase 1 e na sequência de ensino da fase 2 ? Há procedimentos dominantes? Há regularidades na forma como os blocos se sucedem? A partir da análise das respetivas sinopses, eis as conclusões a que chegámos.

\begin{tabular}{|c|c|c|c|}
\hline \multicolumn{2}{|c|}{ Procedimentos de ensino-aprendizagem } & \multicolumn{2}{|c|}{$\begin{array}{l}\text { Sequências } \\
\text { de ensino }\end{array}$} \\
\hline & & \multirow{2}{*}{$\begin{array}{l}\text { Fase } \\
\frac{1}{2} \\
2\end{array}$} & \multirow{2}{*}{$\begin{array}{l}\text { Fase } \\
2 \\
2\end{array}$} \\
\hline $\begin{array}{l}\text { Atividades de } \\
\text { linguagem }\end{array}$ & & & \\
\hline \multirow{4}{*}{$\begin{array}{l}\text { Apropriação } \\
\text { textual }\end{array}$} & Leitura em voz alta & & \\
\hline & Leitura silenciosa & & \\
\hline & Resumo (oral) & & \\
\hline & Assimilação & & \\
\hline \multirow[t]{2}{*}{$\begin{array}{l}\text { Comentário } \\
\text { textual }\end{array}$} & $\begin{array}{l}\text { Compreensão/interpretação/explicação } \\
\text { de texto }\end{array}$ & & \\
\hline & Discussão temática Análise/ de texto & & \\
\hline \multirow[t]{3}{*}{$\begin{array}{l}\text { Produção } \\
\text { textual }\end{array}$} & $\begin{array}{l}\text { Produção de conteúdo (propriamente } \\
\text { dito) }\end{array}$ & 1 & 1 \\
\hline & $\begin{array}{l}\text { Revisão/Transformação } \\
\text { texto/Produção simplificada ou parcial } \\
\text { de texto ou similar }\end{array}$ & & \\
\hline & Produção de um texto inteiro & 1 & 1 \\
\hline \multirow{2}{*}{$\begin{array}{l}\text { Atividades de } \\
\text { metalinguagem }\end{array}$} & & $\mathbf{0}$ & 8 \\
\hline & Definição & & 1 \\
\hline
\end{tabular}



de uma sequência didátical

\begin{tabular}{||l|l|l|l||}
\hline \hline & Análise, comparação e classificação & & 2 \\
\hline & Observação e identificação & & 2 \\
\hline & $\begin{array}{l}\text { Recapitulação, síntese e/ou elaboração } \\
\text { das principais aprendizagens } \\
\text { realizadas e/ou de noções-chave }\end{array}$ & 3 \\
\hline & $\begin{array}{l}\text { Elaboração de uma grelha/critérios de } \\
\text { auxílio na produção de texto e/ou } \\
\text { etapas a seguir }\end{array}$ & & \\
\hline Total & Compreender critérios avaliação & & \\
\hline
\end{tabular}

Da análise do quadro acima, é possível destacar, muito particularmente, os seguintes aspetos: i) procedimentos de ensino-aprendizagem em número reduzido e de diversidade quase nula na sequência de ensino da fase 1; ii) ausência de procedimentos de ensino-aprendizagem de metalinguagem na sequência de ensino da fase 1; iii) procedimentos de ensino-aprendizagem em número relevante e de natureza variada na sequência de ensino da fase 2 . A sequência de ensino da fase 1 alicerça-se, portanto, de forma exclusiva, nos procedimentos "Produção de conteúdo (propriamente dito)" e "Produção de um texto inteiro", situando-se o primeiro no início e o último no fim da sequência. Na sequência de ensino da fase 2 alternam-se, ao longo do tempo, os procedimentos de natureza linguageira e os de ordem não-linguageira, ainda que, na parte final, encontremos a "Produção de um texto inteiro" associada à própria questão da avaliação, grosso modo, das aprendizagens (não) realizadas. A produção de conteúdo (propriamente dito) é, além da própria escrita de um texto inteiro, a única atividade comum às duas sequências de ensino; ainda que, na verdade, o procedimento concreto efetivamente seguido seja distinto em cada uma das fases da pesquisa: i) na sequência de ensino da fase 1 , os alunos são convidados a registar, no quadro negro, "coisas" relacionadas com dois vocábulos que aparecem na última frase de uma obra de leitura integral analisada pela turma, sem que haja qualquer indicação de ordem contextual, digamos, a respeito do texto que será de seguida solicitado aos alunos; ii) na sequência de ensino da fase 2 , a produção de conteúdo acontece, apenas, após a definição de uma questão polémica mais ou menos precisa, em que determinados elementos identificadores de uma situação de comunicação específica são delimitados. Porém, além de haver, então, tal atividade comum - e apesar das diferenças que também existem -, é então evidente o facto de MAS ter realizado um trabalho muito diferente em cada uma das sequências de ensino. Indiscutivelmente, enquanto na sequência de ensino da fase 1, coloca MAS os alunos numa situação de produção de um texto concreto com base tão-só num trabalho prévio em redor da produção de conteúdo, que surge, assim, como o elemento-chave para chegar à escrita de um "comentário" comum, há já, na sequência de ensino da fase 2, um trabalho em torno de algumas das principais características do objeto de ensino em questão - selecionadas com base nas necessidades dos alunos de que MAS tem já conhecimento -, facultando-se a estes mesmos discentes importantes ferramentas para chegarem à escrita do texto solicitado. Por outro lado, os alunos escrevem, de facto, mais vezes na sequência de ensino da fase 2, se comparado, então, com o que acontece na da fase 1. E também não são poucas as atividades propostas na sequência didática que não são selecionadas por MAS; é o que acontece, por exemplo, com a atividade de escrita de uma produção inicial. MAS não parece entrar - pelo menos, de forma completa - nesta forma de fazer, característica do dispositivo da sequência didática. Opção esta justificada pela docente pelo facto de conhecer já muito bem a turma, em termos das suas principais capacidades e dificuldades, no que à escrita diz respeito.

\section{Artigo de opinião considerado}

Com base nos resultados já apresentados, podemos já concluir que, na sequência de ensino da fase 1, MAS considera o artigo de opinião como, grosso modo, um reservatório das "ideias" várias formuladas durante o trabalho de preparação, precisamente, do texto a construir. As "ideias" são percecionadas como o elemento essencial que 
determina o artigo de opinião. Perceção esta que permanece inalterável ao longo da totalidade da sequência de ensino. Na sequência de ensino da fase 2, o artigo de opinião é configurado de forma diferente. Se as "ideias" a figurar num texto - nas palavras de MAS, na sequência de ensino da fase 1 - continuam a ser importantes na construção do artigo de opinião, tal como o "pensar muito" e o "sentir", a verdade é que, na da fase 2, o artigo de opinião surge também como sendo determinado pelos próprios parâmetros que caracterizam a situação de comunicação específica no quadro da qual o texto solicitado é construído. Além disso, a docente também destaca o facto de a avaliação dos textos finais ter fornecido aos alunos numerosas considerações sobre as principais características do artigo de opinião, o que permitiu que os discentes se tornassem mais conscientes dos elementos importantes que devem constar neste género de texto e o que faltava no seu próprio texto.

Ainda que MAS não tenha trabalhado todos os módulos da sequência didática distribuída e tenha insistido em determinadas categorias de conteúdo, é evidente a importante mudança registada no que à sua conceção do objeto entre as duas sequências de ensino diz respeito. MAS parece ter seguido as ideias essenciais propostas na sequência didática facultada. MAS parece ter-se deixado transformar em determinada medida, por esta ferramenta de trabalho, ainda que tal não implique necessariamente que a docente tenha ficado convencida de todas as suas potencialidades.

\section{Algumas considerações finais}

A descrição do que se passa na sala de aula é complexa e difícil de ser compreendida. No entanto, é desta descrição que pode emergir um conhecimento aprofundado do processo de ensino. Assim, a escolha de ferramentas metodológicas que nos permitam tratar e analisar os dados recolhidos torna-se um elemento essencial para ler o mundo da sala de aula. E se é verdade que já existe um número significativo de ferramentas a tal destinados, a sinopse apresenta-se com inúmeras potencialidades. A saber, muito particularmente: i) capacidade de reduzir a massa considerável de dados recolhidos através da observação-vídeo num texto organizado e de razoável dimensão razoável; ii) flexibilidade de adaptação a uma panóplia de investigações; iii) capacidade de gerar pistas fecundas para interpretação dos dados reduzidos e reagrupados em função da lógica específica do estudo realizado. Isto não significa que da elaboração de uma sinopse não decorram também importantes perdas de informação. Afinal, a decomposição das sequências de ensino é feita a partir do filtro específico fornecido pelo nosso particular quadro teórico. Porém, as vantagens advenientes da produção de uma sinopse superam em larga escala, na nossa ótica, as dificuldades e as desvantagens à mesma associadas. É verdade que a sua elaboração representa um trabalho imenso. Mas o certo é que, tal como vimos, permite uma muito maior economia de tempo, quando são consultados os resumos das sequências de ensino em vez de lidas as respetivas transcrições integrais. Além disso, ao ser apresentada em níveis hierárquicos, sob a forma de um quadro, permite uma fácil identificação da organização e eventual repetição dos diferentes objetos disciplinares convocados, facilitando uma rápida apreciação da própria recorrência das atividades conduzidas pelo professor sobre cada (constituinte do) objeto de ensino.

\section{Notas}

1 Texto produzido no âmbito do projeto de pósdoutoramento de Luciana Graça, patrocinado pela Fundação para a Ciência e a Tecnologia, com orientação científica de Luísa Álvares Pereira (Departamento de Educação da Universidade de Aveiro) e de Joaquim Dolz (Faculdade de Psicologia e de Ciências da Educação da Universidade de Genebra). Projeto este desenvolvido também no seio do projeto "PROTEXTOS - Ensino da Produção de Textos no Ensino Básico" (PTDC/CPECED/101009/2008), com coordenação de Luísa Álvares Pereira, financiado pela Fundação para a Ciência e Tecnologia e pelo Programa Operacional Temático Fatores de Competitividade (COMPETE) e comparticipado pelo fundo comunitário Europeu FEDER.

2 "P" por "período", de 45 minutos.

\section{Referências}

BRONCKART, J.-P.; Plazaola Giger, I. La transposition didactique. Histoires et perspectives d'une problématique fondatrice. Pratiques, $n .^{\circ} 97$ 98, p. 35-58, 1998. 
BRONCKART, J.-P.; LAF (ed.). Agir et discours en situation de travail. Genève: Université de Genève, 2004.

CHEVALLARD, Y.; JOHSUA, M.-A. (1991). La transposition didactique: du savoir savant au savoir enseigné. Suivie de Un exemple d'analyse de la transposition didactique. Grenoble: La Pensée Sauvage.

CORDEIRO, G. S.; SCHNEUWLY, B. La mise en activité de deux objets d'enseignement en classe de français: le texte d'opinion et la subordonnée relative. In Actes du 9ème Colloque de l'Association Internationale pour la Recherche en Didactique du Français (AIRDF) (Québec, 2628 août 2004). [CD-ROM]. Québec: Université de Laval, 2005.

DOLZ, J.; NOVERRAZ, M.; SCHNEUWLY, B. $S$ 'exprimer en français: séquences didactiques pour l'oral et pour l'écrit. Corome: De Boeck, 2001.

GOIGOUX, R. Analyser l'activité d'enseignement de la lecture: une monographie. Revue française de pédagogie, 138, p. 125-134, 2002.

GRAÇA, L. O papel das ferramentas didácticas nas práticas docentes de escrita. Tese de Doutoramento, Universidade de Aveiro, Aveiro, 2010.

MACHADO, A. R. O ensino como trabalho: uma abordagem discursiva. Londrina: Eduel, 2004.

MARX, K. Le capital. Livre I. Paris: Quadrige : Presses universitaires de France, 1867/1993.

PEREIRA, L. Á. Escrever em português. Didácticas e práticas. Porto: Edições Asa, 2000.

PEREIRA, L. Á.; CARDOSO, I. (ed.). Reflexão sobre a escrita. $O$ ensino de diferentes géneros de textos. Aveiro: UA Editora, 2013.

PLANE, S.; SCHNEUWLY, B. Regards sur les

Sobre as autoras:

Luciana Graça: doutoranda na Universidade de Aveiro. outils de l'enseignement du français: un premier repérage. Repères, 22, p. 3-17, 2000.

RABARDEL, P. Activités avec instruments et dynamique cognitive du sujet. In Moro, C.; Schneuwly, B.; Brossard, M. (dir.) (ed.). Outils et signes: perspectives actuelles de la théorie de Vygotski, Berne: P. Lang, 1997, p. 35-49.

SCHNEUWLY, B. Les outils de l'enseignant : un essai didactique. Repères, 22, p. 19-38, 2000.

SCHNEUWLY, B.; CORDEIRO, G. S. What object is taught in the classroom? In Analysis of teaching practices on writing in French speaking Switzerland. Proceedings from the 9th International Conference of the EARLI Special Interest Group on Writing (Geneva, 20-22 September 2004) (CD-ROM). Genève, Université de Genève, 2005.

SCHNEUWLY, B.; CORDEIRO, G.; DOLZ, J. A la recherche de l'objet enseigné: une démarche multifocale. Les dossiers des sciences de l'éducation, 14 (dossier Les pratiques enseignantes: analyse des données empiriques coordonné par Yves Lenoir), n. ${ }^{\circ}$ 14, p. 77-93, 2005.

SCHNEUWLY, B.; DOLZ, J.; RONVEAUX, C. Le synopsis: un outil pour analyser les objets enseignés. In Perrin-Glorian, M.-J.; Reuter, Y. (ed.), Les méthodes de recherche en didactiques [actes présentées au Premier Séminaire International sur les Méthodes de Recherches en Didactiques] (pp. 175-189). Paris: Presses Universitaires du Septentrion, 2006.

SCHNEUWLY, B.; THÉVENAZ-CHRISTEN, T. Analyse des objets enseignés. Le cas du français. De boeck université, 2006.

TARDIF, M.; LESSARD, C. Le travail enseignant au quotidien: expérience, interactions humaine et dilemmes professionnels. Bruxelles: De Boeck, 1999. 
Luísa Álvares Pereira: professora da Universidade de Aveiro.

Artigo recebido em novembro de 2013

Artigo aprovado em março de 2014 